\title{
DIMENSI SERVICE EXPERIENCE DALAM MEMBENTUK REPURCHASE INTENTION PADA MD CLINIC BY LAZETA SKIN CARE
}

\author{
Nisa Aghnia \\ Universitas Pendidikan Indonesia \\ Nisa.agnhia@student.upi \\ Lili Adi Wibowo ${ }^{2}$ \\ Universitas Pendidikan Indonesia \\ Liliadiwibowo@upi.edu
}

\begin{abstract}
Purpose - to find out the description of the level of service, experience and repurchase intention in patients MD Clinic by Lazeta Skin Care Branch Kopo and obtained the findings of the magnitude of the influence of dimensions of service experience in shaping the repurchase intention in patients MD Clinic by Lazeta Skin Care Branch Kopo.

Design/methodology/approach - This type of research used are descriptive, verifikatif. The method used was explanatory survey with simple random sampling techniques and sample number of 200 respondents. Data analysis technique used is a structural model with equal tools computer software SPSS AMOS 22.0.

Findings - Based on the research done as a whole, the size of the influence each variable latent directly( standardize direct effect) or indirectly ( standardize indirect effect and the total effect ( standardizes total effect that variable dimensions service experience have a direct influence in forming repurchase intention of 0.769 . Service experience as variables influential dominant must remain controlled directly by company Originality / value - The differences in this study located on an object research, time research, a measuring instrument, literature that used, the theory that is used and the results of the study
\end{abstract}

Keywords: service experience, repurchase intention, skin care, beauty care

Article Type: Research Paper

\section{PENDAHULUAN}

Repurchase intention dianggap sebagai konsep penting dalam literatur pemasaran karena memiliki manfaat dalam bidang praktisi serta penelitian akademik (Iglesias, Singh, \& BatistaFoguet, 2011). Para peneliti saat ini memfokuskan tujuannya untuk mengetahui perilaku pelanggan dalam menghabiskan lebih banyak uang dan membeli lebih sering. Peningkatan repurchase intention menjadi perhatian utama bagi perusahaan-perusahaan yang ingin mendapatkan keunggulan kompetitif serta mengarah ke laba yang lebih tinggi untuk perusahaan (Pappas, Pateli, Giannakos, \& Chrissikopoulos, 2014; Shin, Chung, Oh, \& Lee, 2013).

Perusahaan dapat mengambil banyak manfaat dari upaya meningkatkan repurchase intention. Repurchase intention dapat meningkatkan keuntungan perusahaan dengan hanya mempertahankan lebih dari $5 \%$ pelanggan mereka (Su, Swanson, \& Chen, 2016). Peningkatan $5 \%$ pada repurchase intention dapat meningkatkan keuntungan hingga $25-85 \%$, dan biaya untuk menarik pelanggan baru adalah sekitar lima kali lipat dari mempertahankan yang lama (Kuo, Hu, \& Yang, 2013:170). Perusahaan dapat meningkatkan keuntungannya dengan cara mendorong pelanggan agar termotivasi melakukan pembelian berulang karena repurchase intention dianggap sebagai sumber pengurangan biaya dan sarana pertumbuhan market share serta upaya untuk mendapat dan mempertahankan pelanggan (Abdel-Maguid Lotayif, 2004; Ahmad et al., 2010; Roberts, 2005; AbdelFattah et al., 2014; Ahmed, et al, 2011).

Pemasar umumnya tertarik untuk menyelidiki pengaruh pemasaran terhadap repurchase intention, berbagai produk telah diteliti dalam konteks ini, diantaranya mencakup berbagai produk seperti online shop, luxury goods, perhotelan, resort dan spa, jasa pariwisata dan perbankan (Unjaya \& Santoso, 2013: Syafiah, 2014: Pappas, 2014: Syahid, Andari dan Abullah, 2014: Chan Chu, 2015: Izogo, 2016). Upaya pertama yang harus dilakukan oleh perusahaan dalam meningkatkan repurchase intention pada pelanggannya yaitu mengetahui bagaimana perilaku konsumen yang ditargetkan. Perilaku konsumtif masyarakat saat ini tidak hanya pada konsumsi primer dan sekunder saja, konsumsi kebutuhan tersier pun kini telah hampir 
menggeser konsumsi primer dan sekunder. Salah satu konsumsi wajib wanita adalah perawatan kecantikan (Hidayah \& Imron, 2014).

Para peneliti melakukan berbagai penelitian pada industri kecantikan di berbagai Negara seperti di Arab Saudi, Turki, Perancis, Amerika, Korea, Taiwan, Singapura, India, Indonesia Filipina dan Thailand (Afifah, 2014; Alhedhaif, Lele, \& Kaifi, 2016; Candan, Ünal, \& Erciş, 2013; Chen, 2012).

Perkembangan industri kecantikan di Indonesia tergolong stabil. Menurut Ketua Umum Persatuan Perusahaan Kosmetika Indonesia (Perkomsi) Nurhayati Subakat pertumbuhan industri kosmetik pada kuartal I 2016 melesat tajam diatas pertumbuhan ekonomi nasional (republika.co.id). Perhitungan nilai pasar industri kosmetik di Bursa Efek Indonesia lebih tinggi dibanding data dari Perkosmi. Perkosmi sebelumnya memperkirakan pada 2013 penjualan

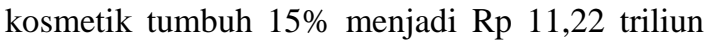
dibanding 2012 sebesar Rp 9,76 triliun.

Fenomena tersebut pada akhirnya memberikan peluang untuk tumbuh berkembangnya pasar dalam industri kecantikan khususnya dalam bentuk usaha klinik kecantikan. Bertumbuhnya usaha ini, memberikan peluang untuk bertambahnya jumlah klinik kecantikan, yang menyebabkan persaingan antar perusahaan dalam memperebutkan jumlah konsumen (Sukotjo \& Radix, 2012).

Bandung merupakan salah satu kota yang memiliki potensi besar untuk para pelaku bisnis di industri kecantikan. Masyarakat Bandung yang dinilai konsumtif serta memiliki tuntutan untuk berpenampilan menarik menjadikan peluang besar bagi para pelaku bisnis untuk membuka usahanya. Banyak klinik kecantikan dan perawatan yang ditawarkan dipasaran dengan berbagai macam merek di Bandung seperti Natasha Skin Care, Erha Clinic, London Beauty Center, DF Clinic, MD Clinic by Lazeta Skin Care, Lis Skin Slimming, Klinik Efra Bandung, Bandung Life Skincare, dan Bandung Carissa Clinic Skin Care.

MD Clinic by Lazeta Skin Care merupakan salah satu klinik kecantikan yang berusaha memenuhi kebutuhan konsumen untuk mendapatkan perawatan kecantikan yang kini dicari oleh banyak kalangan. MD Clinic by Lazeta Skin Care lebih mengedepankan pelayanan terbaik terhadap pasiennya serta selalu meningkatkan kualitas produknya. MD Clinic by Lazeta Skin Care juga menggandeng artis dan selebgram untuk melakukan endorse seperti keluarga Raffi Ahmad, Randy Martin dan Joyagh. Promosi besar pun pernah dilakukan dengan mengadakan "Tour Lazeta Goes To Europe". Memiliki berbagai keunggulan tidak cukup untuk mempertahankan pasien agar kembali melakukan perawatan di Kliniknya.

MD Clinic by Lazeta Skin Care cabang Kopo merupakan salah satu cabang yang mengalami masalah dalam mengupayakan minat kunjungan kembali pasiennya dibandingkan dua cabang lainnya. Data mengenai jumlah pasien Lazeta Skin Care cabang Kopo tahun 2014-2016 dapat dilihat pada Tabel 1

Tabel 1 Data Pasien Md Clinic by Lazeta Skin Care Cabang Kopo Tahun 2014-2016

\begin{tabular}{cc}
\hline Tahun & Jumlah Kunjungan Pasien \\
\hline 2014 & 1674 \\
2015 & 2677 \\
2016 (Jan-Okt) & 4149 \\
\hline
\end{tabular}

Sumber: MD Clinic by Lazeta Skin Care Cabang Kopo, 2016

Menurut Ilma, Kepala Divisi klinik cabang Kopo jumlah pasien di Kopo masih belum memenuhi target dibanding dengan dua cabang lain yang menargetkan 50 pasein setiap harinya, klinik di Kopo adalah yang paling rendah. Jumlah pengunjung MD Clinic by Lazeta Skin Care cabang Kopo memang meningkat setiap tahunnya, namun kebanyakan yang berkunjung adalah pasien baru. Pasien yang telah melakukan perawatan belum tentu melakukan perawatan secara rutin di bulan berikutnya, hal ini menunjukan rendahnya repurchase intention dari Pasien MD Clinic by Lazeta Skin Care cabang Kopo.

Rendahnya repurchase intention harus segera diatasi mengingat semakin kompetitifnya persaingan industri kecantikan di Indonesia. Tingginya pertumbuhan industri kecantikan di Indonesia khususnya Kota Bandung membuat setiap klinik skin care melakukan berbagai strategi dan inovasi untuk dapat memenangkan persaingan. Repurchase intention sangat penting untuk mempertahankan citra dan keberhasilan suatu perusahaan. Salah satu alat ukur agar bertahan dan meningkatkan pangsa pasar adalah dengan adanya perilaku pembelian ulang, hal tersebut menunjukan pentingnya repurchase intention.

Dampak dari terjadinya penurunan tingkat kesetiaan pelanggan dapat berpengaruh pada berpindahnya pelanggan ke merek lain sehingga membawa pengaruh negatif (Paribhasagita \& Lisnawati, 2016). Kehilangan konsumen yang setia tidak hanya akan berpengaruh pada berkurangnya sumber pendapatan perusahaan namun juga dapat berdampak pada image perusahaan yang lemah dibanding pesaing karena tidak mampu mempertahankan konsumennya (Ekaputri, 2015). Mempertahankan konsumen lama lebih menguntungkan dari pada mendapatkan konsumen baru, hal itu dikarenakan biaya dari mempertahankan konsumen yang lama 
lebih murah dibandingkan konsumen baru dan beberapa perusahaan menanggapi hal tersebut dengan membangun hubungan yang saling menguntungkan antara konsumen dengan perusahaan (Suryani, 2013).

Kerugian yang timbul akibat fluktuasi dan penurunan loyalitas adalah berkurangnya sumber pendapatan serta sulitnya memperoleh pelanggan baru (Devindiani \& Wibowo, 2016) sejalan dengan survei yang dilakukan oleh Candra (2008:157) bahwa dibutuhkan biaya 6 kali lebih besar untuk menarik pelanggan baru dan 20 kali lebih besar untuk menarik kembali pelanggan yang sudah kecewa. Manajemen MD Clinic by Lazeta Skin Care jadi semakin menyadari bahwa meningkatkan repurchase intention pasien adalah hal yang penting bagi perusahaan. Faktor-faktor yang dapat menentukan repurchase intention menjadi hal yang penting untuk dipahami (Cheng \& Huang, 2013).

Ketika seseorang berminat untuk melakukan pembelian ulang (repurchase intention) terdapat beberapa hal yang menjadi pertimbangan konsumen. Saran dan Gogula (2016) menyatakan bahwa salah satu faktor yang dapat mempengaruhi repurchase intention adalah service experience. Konsumen berpendapat bahwa hidup itu adalah gabungan dari pengalaman, sehingga setiap kegiatan yang dilakukan oleh konsumen termasuk mengkonsumsi produk atau jasa merupakan pengalaman, apabila pengalaman tersebut mengesankan maka konsumen tidak segan untuk mengkonsumsi barang atau jasa tersebut untuk kesekian kalinya (Smilansky, 2009).

Tujuan penelitian ini adalah: (1) Untuk memperoleh gambaran mengenai tingkat service experience dan repurchase intention, (2) Untuk memperoleh temuan tentang pengaruh service experience dalam membentuk repurchase intention.

\section{KAJIAN PUSTAKA}

Manajemen pemasaran merupakan bagian terpenting bagi perusahaan untuk menjalankan bisnisnya terutama dalam hal memilih pasar, menerapkan target, memperoleh pelanggan hingga mempertahankan pelanggan yang loyal dengan memberikan nilai yang lebih kepada konsumen. Pemasaran adalah kegiatan untuk menciptakan, mengkomunikasikan, memberi dan memproses pertukaran yang bermanfaat bagi organisasi maupun masyarakat (Pride \& Ferrel, 2016).

Pemasaran merupakan ujung tombak dalam sebuah perusahaan, pada saat ini strategi pemasaran lebih menitik beratkan pada konsumen (Haekal \& Widjajanta, 2016). Fokus aktifitas pemasaran dalam rangka mewujudkan tujuan perusahaan adalah berusaha memuaskan pelanggan melalui pemahaman perilaku konsumen (Tjiptono, 2014) yang didefinisikan sebagai perilaku menggunakan, mengevaluasi dan menghabiskan produk dan jasa yang konsumen harapkan akan memuaskan kebutuhan konsumen (Schiffman \& Kanuk, 2012:25). Perilaku konsumen yang satu dengan yang lainnya pasti berbeda dikarenakan kebutuhan dan keinginan akan produk masing-masing individu berbeda (Aprilia \& Wibowo, 2016).

Periset pemasaran telah mengembangkan model tingkat proses keputusan pembelian konsumen melalui tiga tahap yang berbeda namun berhubungan satu sama lain yaitu tahap input (external influence), tahap proses (customer decision making) dan tahap output (postdecision behaviour). Tahap output dalam model pengambilan keputusan konsumen terdiri dari dua macam kegiatan setelah pengambilan keputusan yang berhubungan erat yaitu perilaku membeli dan evaluasi setelah membeli (Schiffman \& Kanuk, 2012:67). Sunarwan (2004) menyatakan repurchase intention terdapat pada tahap pasca konsumsi. Suatu proses keputusan pembelian tidak akan berhenti pada proses konsumsi. Konsumen umumnya melakukan evaluasi terhadap kegiatan konsumsi yang dilakukan atau dikenal sebagai tahapan pasca konsumsi. Pada tahapan tersebut konsumen akan memiliki dua bentuk perilaku yaitu niat melakukan pembelian ulang apabila merasakan kepuasan atau niat tidak melakukan pembelian ulang karena mengalami ketidakpuasan. Pemahaman mengenai perilaku konsumen dalam konteks ketidakpuasan jauh lebih mendalam dari konteks kepuasan konsumen (Lili Adi Wibowo dan Yeni Yuniawati, 2007)

Keputusan pembelian ulang sendiri adalah ketika konsumen memutuskan untuk membeli kembali sebuah produk yang bisa saja didasarkan pada persetujuan konsumen bahwa produk tersebut memenuhi apa yang diinginkan mereka (Schiffman \& Kanuk, 2012). Kecenderungan pelanggan melakukan repurchase intentions dapat menggunakan 3 dimensi dasar yaitu 1) resistance against better alternatives, 2) willingness to pay premium price, dan 3) intention of word of mouth (Mittal \& Kamakura, 2001; Youjae Yi \& La, 2004; Zeithaml, Berry, \& Parasuraman, 1996)

Tujuan utama dari produsen jasa dan pemasaran adalah untuk mengembangkan dan memberi penawaran yang memenuhi kebutuhan dan harapan konsumen, sehingga dapat memastikan kelangsungan hidup ekonomi mereka sendiri, untuk mencapai tujuan tersebut penyedia jasa harus memahami bagaimana konsumen memilih, menentukan pengalaman, dan mengevaluasi penawaran layanan mereka (Zeithaml, Binter, \& Gremler, 2009:50). Salah 
satu faktor yang dapat mempengaruhi perilaku konsumen untuk melakukan repurchase intention khususnya dalam industri jasa adalah dengan meningkatkan service experience pelanggan.

Konsep service experience telah mendapat banyak perhatian dalam bidang jasa baik untuk kepentingan akademisi maupun praktisi (Janet R. McColl-Kennedy, Cheung, \& Ferrier, 2015; Walter, Edvardsson, \& Ostrom, 2010). Banyak penelitian yang mengeksplorasi tentang service experience dengan menilai kepuasan pelanggan atau kualitas layanan namun masih jarang penelitian yang membahas service experience sebagai sunbjek utama penelitiannya (Baron \& Harris, 2010; Johnson, Olsen, \& Andreassen, 2009; Johnston \& Kong, 2011; Kim, Cha, Knutson, \& Beck, 2011; Teng, 2011; Y. Yi \& Gong, 2009).

Service experience dapat diartikan sebagai penilaian pelanggan terhadap semua atribut hubungan langsung dan tidak langsung dengan penyedia layanan yang menjelaskan loyalitas perilaku mereka melalui pembelian berulang (Klaus \& Maklan, 2012). Suatu interaksi yang terjadi antara penyedia jasa dengan konsumen saat proses penggunaan atau penawaran jasa berlangsung sehingga pengalaman jasa yang dirasakan pelanggan tidak dapat dipisahkan dari penyedia jasa atau service provider. Service experience dapat dirasakan setelah konsumen merasakan kualitas suatu jasa. Perusahaan jasa yang baik adalah perusahaan yang mengatur komponen emosi dari pengalaman jasa pelanggan sebanyak komponen yang bersifat fungsional (L. Berry, 2006:2).

Seiring dengan perkembangan perilaku konsumen batas-batas antara pelanggan, perusahaan dan pemasok lainnya menjadi semakin tidak bisa dipisahkan (Achrol \& Kotler, 2012). Konsisten dengan perspektif ini, pandangan bahwa service experience yang turut diciptakan oleh pelanggan dengan penyedia layanan mampu membentuk hubungan timbal balik antara keduanya (Epp \& Price, 2008; J.R. McColl-Kennedy, Vargo, Dagger, Sweeney, \& Van Kasteren, 2012; Price, Arnould, \& Malshe, 2006; Schau, Muñiz, \& Arnould, 2009; Vargo \& Lusch, 2011). Meningkatnya pemahaman mengenai teori penciptaan service experience menekankan bagaimana cara menciptakan layanan yang unik dan kontekstual (Echeverri \& Skålén, 2011; Helkkula, Kelleher, \& Pihlstrom, 2012; Vargo \& Lusch, 2008).

Setiap service experience yang diberikan, dirasakan berbeda oleh setiap pelanggan, Service experience tidak hanya berfokus pada pemberian layanan namun juga tergantung pada faktor lain seperti sosial, budaya, konteks lingkungan, cara pemberian jasa, dan sifat layanan itu sendiri
(Vasconcelos et al., 2015). Meski terdiri dari banyak faktor, semua konseptualisasi pengalaman digunakan untuk mengekspresikan subjektivitas persepsi pelanggan (Jaakkola et al., 2015)

Terdapat empat dimensi dalam membangun service experience yaitu 1) product experience, 2) outcome focus, 3) moment of truth, dan 4) peace of mind (Klaus \& Maklan, 2012; Moore \& Benbasat, 1999)

Membangun sebuah service experience yang positif dalam menjaga hubungan jangka panjang antara perusahaan dan pelanggan menjadi faktor penting untuk menciptakan rasa aman, nyaman dan loyalitas. Berdasarkan uraian tersebut, peneliti selanjutnya akan menjabarkan dalam paradigma penelitian agar mempermudah proses peneitian.

Gambar 1. Paradigma Penelitian

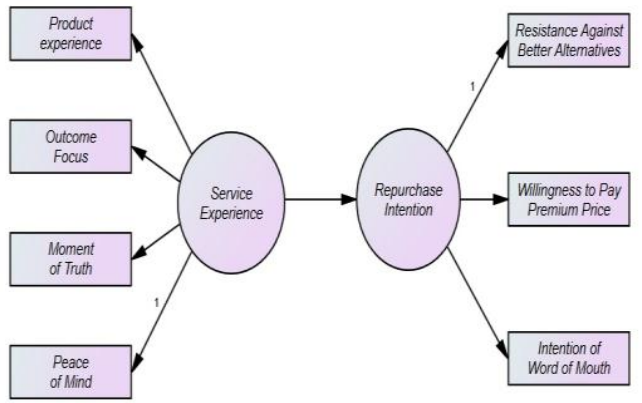

\section{METODE PENELITIAN}

Penelitian ini dilakukan untuk mengalanisis dimensi service experience dalam membentuk repurchase intention pada Pasien MD Clinic by Lazeta Skincare cabang Kopo. Variabel bebas (independent variable) atau variabel eksogen yang terdapat pada penelitian ini yaitu service experience dengan dimensi product experience, outcome focus,moment of truth dan peace of mind. Sedangkan variabel terikat (dependent variable) atau variabel endogen pada penelitian ini yaitu resistance against better alternatives, willingness to pay premium price, dan intention of word of mouth.

Objek/unit analisis pada penelitian ini yaitu Pasien MD Clinic by Lazeta Skincare cabang Kopo. Penelitian ini dilakukan pada kurun waktu kurang dari satu tahun, sehingga teknik pengumpulan data yang digunakan pada penelitian ini adalah cross-sectional method. Teknik yang digunakan dalam penelitian ini adalah teknik propability yaitu simple random dengan jumlah sampel sebanyak 200 responden. Teknik pengumpulan data yang digunakan adalah studi kepustakaan, studi lapangan dengan penyebaran kuesioner, dan studi literatur. Sedangkan teknik analisis data yang dilakukan 
adalah analisis deskriptif dan verifikatif. Analisis data verifikatif menggunakan SEM dengan bantuan software AMOS 22.0 for windows.

\section{HASIL PENELITIAN DAN PEMBAHASAN}

\section{A. Pembahasan Deskriptif}

\section{a. Service Experience}

Berdasarkan hasil penelitian yang bersifat empirik mengenai dimensi service experience, menunjukan bahwa dimensi peace of mind memberikan kontribusi terbesar dalam service experience, melalui kemampuan untuk mengontrol emosi pasien saat terjadi masalah.

\section{b. Repurchase Intention}

Berdasarkan hasil penelitian yang bersifat empirik mengenai dimensi repurchase intention, menunjukan bahwa dimensi resistance against better alternaives memberikan kontribusi terbesar dalam repurchase intention, melalui keinginan untuk tetap menggunakan jasa meski banyak kemungkinan tawaran menarik dari pesaing.

\section{B. Pembahasan Verifikatif}

Pengujian hipotesis penelitian ini dilakukan untuk mengetahui besarnya pengaruh service experience terhadap repurchase intention. Pengujian hipotesis secara simultan dilakukan menggunakan teknik analisis Structure Equation Model (SEM). Hipotesis penelitian ini adalah service experience berpengaruh secara simultan dan parsial terhadap repurchase intention. Hipotesis ini diuji secara simultan maupun parsial dengan menggunakan AMOS 22.0 for windows.

Pengukuran Model Secara Keseluruhan (Goodness of Fir Indices)

Pengujian validitas measurement model untuk menguji kesesuaian model atau dapat disebut goodness of fit (GOF) memiliki tujuan untuk mengetahui seberapa besar variabel manifest (indikator) memberikan dukungan terhadap variabel latent (konstruk), dengan kata lain seberapa fit model dengan data yang diperoleh dalam penelitian. Uji kesesuaian dan statistik dilakukan menggunakan fit indeks untuk mengukur kesesuian model yang diajukan. Berdasarkan hasil pengolahan data dengan menggunakan AMOS 22.0 for windows diperoleh hasil untuk pengujian model sebagai berikut:

Tabel 2. Hasil Evaluasi Model dengan Goodness Of Fit Measure

\begin{tabular}{ccccc}
\hline No & $\begin{array}{c}\text { Goodness-of- } \\
\text { Fit Measures }\end{array}$ & $\begin{array}{c}\text { Cut-off } \\
\text { value }\end{array}$ & Hasil & $\begin{array}{c}\text { Evaluasi } \\
\text { Model }\end{array}$ \\
\hline \multicolumn{3}{c}{ Absolute Fit Measures } \\
1 & $\begin{array}{c}\text { Chi-square } \\
\left(X^{2}\right)\end{array}$ & $\begin{array}{c}\text { Sekecil } \\
\text { Mungkin } \\
\text { (good fit })\end{array}$ & 86.868 & Tidak Fit
\end{tabular}

\begin{tabular}{|c|c|c|c|c|}
\hline No & $\begin{array}{l}\text { Goodness-of- } \\
\text { Fit Measures }\end{array}$ & $\begin{array}{l}\text { Cut-off } \\
\text { value }\end{array}$ & Hasil & $\begin{array}{c}\text { Evaluasi } \\
\text { Model }\end{array}$ \\
\hline 2 & P Value & $>0,05$ & 0.000 & Tidak Fit \\
\hline 3 & GFI & $\begin{array}{c}\mathrm{GFI} \geq 0.90 \\
\text { good fit, } \\
0.80 \leq \mathrm{GFI} \\
<0.90 \\
\text { marginal } \\
\text { fit }\end{array}$ & 0.891 & Marginal Fit \\
\hline 4 & RMSEA & $\leq 0.08$ & 0.169 & Good Fit \\
\hline \multicolumn{5}{|c|}{ Incremental Fit Measures } \\
\hline 5 & TLI & $\begin{array}{c}\text { TLI } \geq 0.90 \\
\text { good fit, } \\
0.80 \leq \mathrm{LI} \\
<0.90 \\
\text { marginal } \\
\text { fit }\end{array}$ & 0.870 & Marginal Fit \\
\hline 6 & AGFI & $\geq 0.90$ & 0.766 & Tidak Fit \\
\hline 7 & CFI & $\begin{array}{c}\mathrm{CFI} \geq 0.90 \\
\text { good fit, } \\
0.80 \leq \mathrm{CFI} \\
<0.90 \\
\text { marginal } \\
\text { fit }\end{array}$ & 0.919 & Good Fit \\
\hline \multicolumn{5}{|c|}{ Parsimonious Fit Measures } \\
\hline 8 & PGFI & $\begin{array}{c}\text { PGFI < } \\
\text { GFI }\end{array}$ & 0.414 & Good Fit \\
\hline 9 & PNFI & $\begin{array}{l}\text { Semakin } \\
\text { tinggi } \\
\text { semakin } \\
\text { baik, } \\
\text { dibandingk } \\
\text { an dengan } \\
\text { alternatif } \\
\text { model }\end{array}$ & 0.562 & Good Fit \\
\hline
\end{tabular}

Meski tidak seluruh ukuran Goodness-of-Fit sesuai dengan rekomendasi cut-off value, tetap dapat disimpulkan bahwa model secara keseluruhan sudah fit karena menurut Malhotra (2010:733), gunakan paling sedikit 1 ukuran yang bersifat absolut baik (misalnya: GFI, AGFI), 1 ukuran yang bersifat absolut buruk (misalnya: Chi-Squares, RMSR, SRMR, RMSEA) dan 1 ukuran yang bersifat komparatif (misalnya: NFI, NNFI, CFI, TLI, RNI).

Selanjutnya yaitu spesifikasi model bagian dari model SEM yang menggambarkan hubungan antara variabel laten dengan indikatorindikatornya. Tahapan ini yang harus dilakukan adalah definisikan variabel-variabel laten yang ada dalam penelitian, yaitu dimensi service experience dan repurchase intention. Penelitian ini hubungan antara setiap variabel dengan variabel-variabel yang teramati atau indikator yaitu product experience $\left(\mathrm{X}_{1}\right)$, outcome focus $\left(\mathrm{X}_{2}\right)$, moment of truth $\left(\mathrm{X}_{3}\right)$, dan peace of mind 
$\left(\mathrm{X}_{4}\right)$ yang merupakan indikator dari variabel laten faktor service experience (X) serta resistance against better alternatives $\left(\mathrm{Y}_{1}\right)$, willingness to pay premium price $\left(\mathrm{Y}_{2}\right)$, dan intention of word of mouth $\left(\mathrm{Y}_{3}\right)$ yang termasuk indikator repurchase intention (Y). Berikut adalah tabel yang menunjukan hasil perhitungan bobot faktor, regresi, validitas, dan reliabilitas dari masingmasing variabel indikator.

Tabel 3. Pengujian Validitas Koefisien Bobot Faktor

\begin{tabular}{lclc}
\hline & & & Estimate \\
\hline $\begin{array}{l}\text { Repurchase } \\
\text { Intention }\end{array}$ & $<---$ & Service Experience & 0.769 \\
POM & $<---$ & Service Experience & 0.790 \\
MOT & $<---$ & Service Experience & 0.931 \\
OF & $<---$ & Service Experience & 0.875 \\
PE & $<---$ & Service Experience & 0.735 \\
RABA & $<---$ & Repurchase Intention & 0.779 \\
WPPP & $<---$ & Repurchase Intention & 0.858 \\
IWOM & $<---$ & Repurchase Intention & 0.669 \\
\hline
\end{tabular}

Sumber: Pengolahan AMOS, 2016

Berdasarkan Tabel 4 diketahui dalam mengukur variable laten service experience bahwa moment of truth $\left(\mathrm{X}_{3}\right)$ merupakan indikator yang paling valid dengan nilai standardized loading estimate 0.931, sedangkan product experience $\left(\mathrm{X}_{1}\right)$ menunjukan validitas paling kecil dalam mengukur service experience dengan nilai standardized loading estimate 0.735. Mengukur variable laten repurchase intention, willingness to pay premium price $\left(\mathrm{Y}_{2}\right)$ merupakan indikator yang paling valid dengan nilai standardized loading estimate 0.858 dan intention of word of mouth $\left(\mathrm{Y}_{3}\right)$ menunjukan validitas paling kecil nilai standardized loading estimate sebesar 0.669. Nilai tertinggi dan terendah dimensi tersebut menunjukan nilai standardized loading estimate $>0.5$ yang menunjukan bahwa dimensi konstruk mampu merefleksiakn variable laten.

Pengujian validitas dilakukan pula pengujian reliabilitas terhadap variabel laten service experience dan repurchase intention uji reability dilakukan untuk menguji keandalan dan konsistensi data. Pengujian reliabilitas pada teknik analisis data SEM ini dilakukan dengan menghitung jumlah standard loading factor dan kesalahan sehingga didapatkan nilai construct reliability dan variance extratct. Nilai reliable construct yang direkomendasikan adalah di atas 0,70 , sedangkan untuk nilai variance extratct yang direkomendasikan di atas 0,50. Apabila nilai mampu melebihi rekomendasi, dapat dikatakan terdapat pengaruh yang saling signifikan.

Hasil pengujian reabilitas yang diketahui bahwa nilai reliability construct untuk variabel service experience 1,13 , sedangkan untuk variabel repurchase intention sebesar 1,19 , berdasarkan hal tersebut maka nilai tersebut di atas 0,70 yang direkomendasikan. Nilai varience extract pada variabel service expeirence sebesar 6,18 dan untuk variabel repurchase intention sebesar 17,1. Nilai variance extract dari kedua variabel melebihi nilai 0,60 yang direkomendasikan. Berdasarkan hal tersbut dapat dikatakan bahwa kedua variabel laten dalam penelitian ini adalah reliable dan terdapat saling pengaruh yang signifikan.

\section{Hasil Model Struktural}

Terdapat pengaruh antara dimensi service experience dan minat menggunakan kembali pada pasien jasa kiriman MD Clinic by Lazeta Skin Care cabang Kopo.Taksiran parameter pada setiap jalur ditampilkan pada Gambar berikut:

Gambar 2. Diagram Taksiran Parameter Service Experience Terhadap Repurchase Intention

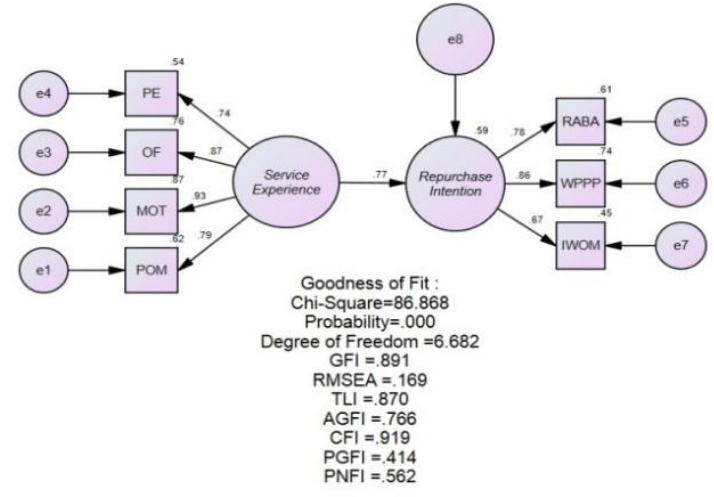

Sumber: Hasil pengolahan data AMOS 2016

Hasil yang diperoleh menunjukkan bahwa semua taksiran parameter pada diagram jalur tersebut adalah signifikan. Hasil tersebut mendukung teori yang telah dilakukan pada penelitian sebelumnya oleh (Saran \& Gogula, 2016) menyatakan bahwa service experience mempunyai pengaruh yang signifikan terhadap repurchase intention.

Melalui program statistik AMOS dapat dianalisis dan dihitung hasil bobot regresi antar variabel laten yang sering disebut sebagai estimasi loading factors atau lamda value. Derajat bebas atau degree of freedom (df), nilai C.R atau t-hitung juga dapat diketahui. Berdasarkan signifikansi t-hitung dengan nilai probabilitas (p) $=0,05$. Hasil bobot regresi uji kausalitas sebagai berikut:

Tabel 4. Evaluasi Bobot Regresi Uji Kausalitas

\begin{tabular}{ccccccc}
\hline & & & Estimate & S.E. & C.R. & P \\
\hline $\mathrm{X}$ & $-->$ & $\mathrm{Y}$ & 0.970 & .109 & 8.914 & $* * *$ \\
\hline
\end{tabular}

Sumber: Pengolahan AMOS, 2016

Berdasarkan Tabel 4.20 dapat dilihat bahwa nilai hitung (S.E) sebesar 0,109 > t tabel pengaruh 
yang signifikan service experience terhadap repurchase intention secara signifikan karena thitung (C.R) lebih besar dari nilai probabilitas $<0,05$, sebaliknya nilai $\mathrm{p}$-value harus lebih kecil dari 0,05 .

Besarnya pengaruh masing-masing variabel laten secara langsung (standardize direct effect) maupun tidak langsung (standardize indirect effect) serta efek total (standardizes total effect) bahwa variabel faktor-faktor service experience memiliki pengaruh langsung terhadap repurchase intention sebesar 0.769. Secara keseluruhan model konseptual persamaan struktural yang dirancang berdasarkan goodness of fit atau pengujian model penelitian memenuhi kelayakan model (fit) yang berarti sesuai dengan kondisi empiris.

Berdasarkan model penelitian, dimensi service experience positif dalam membentuk repurchase intention. Atas dasar analisis regression weight yang dilakukan, ditemukan uji$\mathrm{t}$ atas variabel-variabel maka dapat diambil keputusan bahwa hipotesis nol $\left(\mathrm{H}_{0}\right)$ ditolak dan $\mathrm{H}_{\mathrm{i}}$ diterima, karena sesuai dengan kriteria penerimaan hipotesis yaitu nilai Critical Ratio (C.R.) $\geq 1,99773$ atau nilai probabilitas $(\mathrm{P}) \leq$ 0,05 . Sehingga dapat dikatakan bahwa terdapat hubungan linear antara dimensi service experience dalam membentuk repurchase intention.

Service experience akan mempengaruhi repurchase intention. Hal ini sejalan dengan Chang, Lee. Y, J., C.L., L., \& Chen. C. Y, (2010) yang mengatakan bahwa adanya hubungan yang positif antara pengalaman konsumen akan suatu produk terhadap kecenderungan konsumen untuk kembali melakukan pembelian terhadap produk yang dievaluasi baik. Pengalaman pelanggan secara signifikan dapat mempengaruhi niat pelanggan untuk melakukan pembelian ulang dimasa depan (L. L. Berry, Carbone, \& Haeckel, 2002). Penelitian lain juga menyatakan bahwa mayoritas repurchase intention dipengaruhi oleh pengalaman positif dari penyedia layanan (Lee \& $S$, 2012) sejalan dengan yang diungkapkan oleh Saran \& Gogula (2016) bahwa service experience merupakan salah satu faktor yang dapat mempengaruhi repurchase intention.

\section{KESIMPULAN}

Berdasarkan hasil penelitian di pembahasan dikemukakan kesimpulan sebagai berikut:

Gambaran mengenai service experience MD Clinic by Lazeta Skin Care cabang Kopo dapat dilihat dari dimensinya yang terdiri dari product experience, outcome focus, moment of truth, dan peace of mind berada pada kategori tinggi. Artinya penilaian service experience menurut Pasien MD Clinic by Lazeta Skin Care cabang
Kopo dinilai baik. Dimensi moment of truth merupakan dimensi yang memiliki penilaian paling tinggi dalam membentuk repurchase intention MD Clinic by Lazeta Skin Care cabang Kopo, sedangkan dimensi yang memiliki penilaian paling rendah dalam membentuk repurchase intention adalah product experience. Gambaran repurchase intention pada Pasien MD Clinic by Lazeta Skin Care cabang Kopo yang diukur berdasarkan resistance against better alternatives, willingness to pay premium price, dan intention to word of mouth berada pada kategori cukup tinggi. Artinya penilaian repurchase intention secara keseluruhan berada pada kategori cukup tinggi sehingga dinilai cukup baik. Dimensi willingness to pay premium price secara keseluruhan memiliki nilai paling tinggi, sedangkan untuk dimensi yang memiliki nilai terendah adalah intention to word of mouth.

Service experience memiliki pengaruh yang positif terhadap repurchase intention MD Clinic by Lazeta Skin Care cabang Kopo dengan dimensi yang membangun service experience memiliki pengaruh yang positif terhadap repurchase intention MD Clinic by Lazeta Skin Care cabang Kopo. Dengan masing-masing dimensi yaitu: 1) product experience, 2) outcome focus, 3) moment of truth, dan 4) peace of mind

\section{DAFTAR PUSTAKA}

AbdelFattah, F. A., Rahman, M. S., Mohamad, O., \& Aziz, N. (2014). Factors Determining Customers' Repurchase Intention of Healthcare Insurance Products in Malaysia. Proceedings of the Australian Academy of Business and Social Sciences Conference 2014 (in Partnership with The Journal of Developing Areas), (ISBN 978-0-9925622$0-5)$.

Abdel-Maguid Lotayif. (2004). Factors that affect the selection of defensive marketing strategies: evidence from the Egyptian banking sector. Journal of American Academy of Business, 4, 152-158.

Achrol, R. S., \& Kotler, P. (2012). Frontiers of the marketing paradigm in the third millennium. Journal of the Academy of Marketing Science, 40(1), 35-52.

Afifah, R. N. (2014). Analisis pengaruh kualitas produk, kualitas pelayanan dan promosi terhadap kepuasan konsumen untuk meningkatkan loyalitas pelanggan. UNIVERSITAS DIPONEGORO.

Ahmad, Z., Ahmed, I., Nawaz, M., Usman, A., Shaukat, M., \& AN. (2010). Impact of Service Quality of Short Messaging Service on Customers Retention; An Empirical Study of Cellular Companies of Pakistan. International Journal of Business and 
Management, $\quad 5(6)$

154.

http://doi.org/10.5539/ijbm.

Ahmed, I., Shankat, M. Z., Nawaz, M. M., Ahmed, N., \& Usman, A. (2011). Determinants of The Satisfaction and Repurchase Intentions of Users of Short Messenger Services (SMAS): A Study in The Telecom Sector of Pakistan. International Journal of Management, 28, 763-772.

Alhedhaif, S., Lele, U., \& Kaifi, B. A. (2016). Brand Loyalty and Factors Affecting Cosmetics Buying Behavior of Saudi Female Consumers. Journal of Business Studies Quarterly, 7(3), 2152.

Aprilia, L., \& Wibowo, L. A. (2016). Pengaruh Faktor Individu dan Sosial Terhadap Keputusan Menggunakan. Journal of Business Management and Enterpreneurship Education, 1(1), 202212.

Baron, S., \& Harris, K. (2010). Toward an understanding of consumer perspectives on experiences. Journal of Service Marketing, 24(7), 518-531.

Berry, L. (2006). Managing Service Experience Clues. Wharton: University of Pennsylvania.

Berry, L. L., Carbone, L. P., \& Haeckel, S. H. (2002). Managing the total customer experience. MIT Sloan Management Review, 43(3), 85-89.

Candan, B., Ünal, S., \& Erciş, A. (2013). Analysing the relationship between consumption values and brand loyalty of young people: A study on personal care products. European Journal of Research on Education, 29-46.

Candra, H. (2008). Marketing untuk Orang Awam. Jakarta: Maxikom.

Chang, L., Lee. Y, J., C.L., C., L., H. C., \& Chen. C. Y. (2010). The Influence of Customers Emotional Response and Social Norm on Repurchase Intention: A case of Cigarette Repurchase in Taiwan. The Journal of International Management Studies, 5(2).

Chen, Y. (2012). 2012. The Study on Brand Marketing Strategy of French Cosmetic An Example of Christian Dior. Departemen of Public Relations and Advertising.

Cheng, H. H., \& Huang, S. W. (2013). Exploring Antecedents and Consequence of Online Group-Buying Intention: An Extended Perspective on Theory of Planned Behavior. International Journal of Information Management, 33(1), 185-198.

Devindiani, E., \& Wibowo, L. A. (2016). PENGARUH EXPERIENTIAL MARKETING TERHADAP CUSTOMER
SATISFACTION SERTA DAMPAKNYA PADA CUSTOMER LOYALTY ( Survei pada Pengguna Smartphone di Komunitas Online Apple dan Samsung Regional Bandung ). Journal of Business Management and Enterpreneurship Education, 1(1), 147-157.

Echeverri, P., \& Skålén, P. (2011). Co-creation and co-destruction: a practice-theory based study of interactive value formation. Marketing Theory, 11(3), 351-373.

Ekaputri, J. J. P. (2015). Pengaruh Customer Delight terhadap Loyalitas Tamu Hotel Grand Loyal Panghegar. Universitas Pendidikan Indonesia.

Epp, A. M., \& Price, L. P. (2008). Family identity: a framework of identify interplay in consumption practices. Journal of Consumer Research, 35(1), 50-70.

Haekal, A., \& Widjajanta, B. (2016). Pengaruh Kepercayaan dan Persepsi Risiko Terhadap Minat Membeli Secara Online pada Pengunjung Website Classifieds di Indonesia. Journal of Business Management and Enterpreneurship Education, 1(1), 181-193.

Helkkula, A., Kelleher, C., \& Pihlstrom, M. (2012). Characterizing value as an experience - implications for researchers and managers. Journal of Service Research, 15(1), 59-75.

Hidayah, N., \& Imron, A. (2014). Gaya Hidup Mahasiswi Pengguna Perawatan Wajah di Klinik Kecantikan Kota Surabaya.

Iglesias, O., Singh, J. J., \& Batista-Foguet, J. M. (2011). The role of brand experience and affective commitment in determining brand loyalty. Journal of Brand Management, 18(8), 570-582.

Jaakkola, E., Helkkula, A., \& Aarikka-Stenroos, L. (2015). Service experience co-creation: conceptualization, implications, and future research directions. Journal of Service Management, 26(2), 182-205. http://doi.org/10.1108/JOSM-12-2014-0323

Johnson, M. D., Olsen, L. L., \& Andreassen, T. . (2009). Joy and disappointment in the hotel experience: managing relationship segment. Managing Service Quality, 19(1), 4-30.

Johnston, R., \& Kong, X. Y. (2011). The customer experience: a road-map for improvement. Managing Service Quality, 21(1), 5-24.

Kim, D. J., Ferrin, D. L., \& Rao, H. R. (2003). No Title. Antecedents of Consumer Trust in Bto-C Electronic Commerce, Preceeding of Ninth Americas Conference on Information System, 157-167.

Kim, S. H., Cha, J. M., Knutson, B. J., \& Beck, J. 
A. (2011). Development and testing of the consumer experience index (CEI). Managing Service Quality, 21(2), 112-132.

Klaus, P., \& Maklan, S. (2012). EXQ : a multipleitem scale for assessing service experience. Journal of Service Management, 23(1), 533.

http://doi.org/10.1108/09564231211208952

Kuo, Y.-F., Hu, T. L., \& Yang, S.-C. (2013). Effect of inertia and satisfaction in female online shoppers on repeat-purchase intention. (The moderating roles of worldof-mouth and alternative attraction). Managing Service Quality Vol., 23(3), 168187.

Lee, H. J., \& S, K. M. (2012). The effect of brand experience on brand relationship quality. Academy of Marketing Studies, 16(1), 8798

Lili Adi Wibowo dan Yeni Yuniawati. (2007). The Influence of Tourist Product Attribute and Trust to Tourist Satisfaction and Loyalty A Study of Mini Vacation in Bandung Oleh: Journal of Chemical Information and Modeling, 53(9), 16891699.

http://doi.org/10.1017/CBO9781107415324 .004

Malhotra, N. K. (2010). Marketing Research : An Applied Orientation (Sixth Edit). Pearson Education.

McColl-Kennedy, J. R., Cheung, L., \& Ferrier, E. (2015). Co-creating service experience practices. Journal of Service Management, 26(2), 249-275. http://doi.org/10.1108/JOSM-08-2014-0204

McColl-Kennedy, J. R., Vargo, S. L., Dagger, T. S., Sweeney, J. C., \& Van Kasteren, Y. (2012). Health care customer value cocreation practice styles. Journal of Service Research, 15(4), 370-389.

Mittal, W. A. V., \& Kamakura. (2001). Satisfaction, Repurchase Intent, and Repurchase Behavior: Investigating the Moderating Effect of Customer Characteristics. Journal of Marketing Research, 38(1), 131-142.

Moore, G., \& Benbasat, I. (1999). Development of an instrument to measure the perceptions of adopting an information technology innovation. Information System Research, 2(3), 192-222.

Pappas, I. O., Pateli, A. G., Giannakos, M. N., \& Chrissikopoulos, V. (2014). Moderating effects of online shopping experience on customer satisfaction and repurchase intentions. International Journal of Retail \& Distribution Management, 42(3), 187204. http://doi.org/10.1108/IJRDM-03-
2012-0034

Paribhasagita, T., \& Lisnawati. (2016). PENGARUH CUSTOMER RELATIONSHIP MANAGEMENT TERHADAP LOYALITAS NASABAH ( Survei pada Nasabah Asuransi Jiwa Prudentual Cabang Kota Bandung ). Journal of Business Management and Enterpreneurship Education, 1(1), 37-53.

Price, L., Arnould, E., \& Malshe, A. (2006). "Towards a resource-based theory of the customer", in Lusch, R.F. and Vargo, S.L. (Eds), The New Dominant Logic in Marketing. (M.E.Sharpe, Ed.). New York: Armonk.

Pride, W. M., \& Ferrel, O. C. (2016). Marketing. United States: Cengage Learning.

Roberts, J. H. (2005). Defensive Marketing.

Saran, R., \& Gogula, R. (2016). The Impact of Service Experience and Brand Experience on Satisfaction Service Brand Attitude Brand Equity and Repurchase Intention. ICFAI Foundation forHigher Education.

Schau, H. J., Muñiz, A. M. J., \& Arnould, E. . (2009). How brand community practices create value. Journal of Marketing, 73(5), 30-51.

Schiffman, L. G., \& Kanuk, L. L. (2012). Consumer Behaviour. Pearson Education.

Shin, J. I., Chung, K. H., Oh, J. S., \& Lee, C. W. (2013). The Effect of site quality on Repurchase Intentionin Internet Shopping through mediating variables: The Case of University Student in South Korea. Management, International Journal of Information, 33, 453-463.

Smilansky, S. (2009). Experiential Marketing: A Practical Guide to Interactive brand Experience. Universitas Indiana: Kogan Page.

Su, L., Swanson, S. R., \& Chen, X. (2016). The effects of perceived service quality on repurchase intentions and subjective wellbeing of Chinese tourists: The mediating role of relationship quality. Tourism Management, $\quad 52, \quad 82-95$. http://doi.org/10.1016/j.tourman.2015.06.01 2

Sukotjo, H., \& Radix, S. (2012). Analysis-7P Marketing Mix (Product, Price, Promotion, Place, Participant, Process and Physical Evi-dence) Against Product Purchase Decision Teta Beauty Clinic. Journal of Economics and Business Management, 216-228.

Sunarwan, U. (2004). Perilaku Konsumen: Teori dan Penerapannya dalam Pemasaran. Bogor: Ghalia Indonesia.

Suryani, T. (2013). Perilaku Konsumen di Era 
Internet. Yogyakarta: Graha Ilmu.

Teng, C. . (2011). Commercial hospitality in restaurants and tourist accommodation: perspectives from international consumer experience in Scotland. International Journal of Hospitality Management, 30(4), 866-874.

Tjiptono, F. (2014). Pemasaran Jasa: Prinsip, Penerapan dan Penelitian. Yogyakarta: Penerbit Andi.

Unjaya, D., \& Santoso, L. (2013). 2013. Analisis Pengaruh Satisfaction, Trust dan Commitment terhadap Repurchase Intention Pelanggan Tetap Hotel Raden Wijaya Mojokerto. Universitas Kristen Petra.

Van Doorn, J., Lemon, K. N., Mittal, V., Nass, S., Pick, D., Pirner, P., \& Verhoef, P. C. (2010). Customer engagement behavior: theoretical foundations and research directions. Journal of Service Research, 13(3), 253-266.

Vargo, S. L., \& Lusch, R. F. (2008). Servicedominant logic: continuing the evolution. Journal of the Academy of Marketing Science, 36(1), 1-10.

Vargo, S. L., \& Lusch, R. F. (2011). It's all B2B $\ldots$ and beyond: toward a service perspective of the market. Industrial Marketing Management, 40(2), 181-187.

Vasconcelos, A. M. de, Barichello, R., Lezana,
A., Forcellini, F. A., Ferreira, M. G. G., \& Miguel, P. A. C. (2015). Conceptualisation of the service experience by means of a literature review. Benchmarking: An International Journal, 22(7), 1301-1314. http://doi.org/10.1108/BIJ-08-2013-0078

Walter, U., Edvardsson, B., \& Ostrom, A. (2010). Drivers of customers service experiences: a study in the restaurant industry. Managing Service Quality, 20(3), 236-258.

Yi, Y., \& Gong, T. (2009). An integrated model of customer social exchange relationship: the moderating role of customer experience. Service Industries Journal, 29(11), 15131528.

Yi, Y., \& La, S. (2004). What influences the relationship between customer satisfaction and repurchase intention? Investigating the effects of adjusted expectations and customer loyalty. Psychology and Marketing, 21(5), 351-373.

Zeithaml, V. ., Binter, M. ., \& Gremler. (2009). Services Marketing: Integrating Customer Focus Across the Firm, 15. New York: McGraw Hill.

Zeithaml, V. A., Berry, L. L., \& Parasuraman. (1996). The Behavioral Concequence of Service Quality. Journal of Marketing, 60(2). 